\title{
AUTISMO: UMA VISÃO PSICANALÍTICA E DIFICULDADES NA INTERVENÇÃO CLÍNICA ${ }^{1}$
}

\author{
Tayná de Oliveira Freitas - UNIFSA \\ André Luiz dos Santos Lima - UNIFSA \\ Débora de Lima Lira - UNIFSA \\ Renata Madureira Lins de Araújo - UNIFSA
}

\begin{abstract}
RESUMO
Autismo é um transtorno neurológico onde a estrutura do cérebro encontra-se desorganizada, fazendo assim com que seu funcionamento não seja totalmente correto principalmente nos processos sociais do ambiente. A primeira vez que este foi mencionado era somente um sintoma básico da esquizofrenia. $O$ presente artigo traz todo contexto histórico do autismo e uma perspectiva psicanalítica, com o principal objetivo de pontuar as principais dificuldades na intervenção do psicólogo clínico. Trata-se de uma pesquisa qualitativa feita através de revisão bibliográfica de livros e artigos identificados por meio de buscas efetuadas nas bases Pepsic, Scielo e Google Acadêmico.
\end{abstract}

Palavras-Chave: Autismo. Psicologia Clínica. Psicanálise.

\begin{abstract}
Autism is a neurological disorder where the brain structure is disorganized, so that its functioning is not entirely correct especially in the social processes of the environment. The first time this was mentioned was just a basic symptom of schizophrenia. This article presents the entire historical context of autism and a psychoanalytical perspective, with the main objective of pointing out the main difficulties in the intervention of the clinical psychologist. This is a qualitative research made through bibliographic review of articles and books identified through searches conducted in Pepsic, Scielo and Academic Google databases.
\end{abstract}

Keywords: Autism. Clinical Psychology. Psychoanalysis.

\footnotetext{
${ }^{1}$ Trabalho apresentado no Congresso Brasileiro Ciência e Sociedade (CBCS 2019), promovido pelo Centro Universitário Santo Agostinho, de 03 a 05 de outubro de 2019, em Teresina-PI.

2 Graduanda de Psicologia - 6 ${ }^{\circ}$ Período, UNIFSA. taynafreitas@ hotmail.com

Graduando de Psicologia - $6^{\circ}$ Período, UNIFSA. andre_lima098@outlook.com

Graduanda de Psicologia - 6 ${ }^{\circ}$ Período, UNIFSA. deboralira1@ hotmail.com

Graduanda de Psicologia - 6º Período, UNIFSA. renatalinsaraujo@gmail.com
} 
ANAIS CBCS 2019 | 3 a 5 de outubro de 2019 | Centro Universitário Santo Agostinho - Teresina - PI

\section{INTRODUÇÃO}

Atualmente nota-se um debate mais ativo sobre o autismo, principalmente quando se trata da inclusão do indivíduo autista no meio social. $O$ autismo é classificado cientificamente, de acordo com o DSM V, como Transtorno do Espectro Autista (TEA), mas a psicanálise não utiliza esse termo, se caracterizando-se por dificuldades na comunicação, na socialização e no comportamento. O transtorno é multicausal e presente desde o nascimento ou notado geralmente nos primeiros trinta dias de vida, a criança tem um atraso na fala, na compreensão e incapacidade de criar relacionamentos sociais. Uma das características predominantes é não conseguir manter o contato visual e gestos estereotipados.

O comportamento varia de acordo com a fase na qual o indivíduo se encontra, porém tratando-se de traços gerais vale enfatizar a importância do diagnóstico precoce para que não haja maior prejuízo na linguagem e no âmbito social. Psicólogos e psiquiatras defendem que existe uma relação entre autismo, genética, meio ambiente e sociedade.

A primeira vez que viu-se falar do termo autismo na psicanálise foi quando este era considerado um sintoma básico da esquizofrenia. Para Freud a psicose é a criação de outra realidade, e para Bleuler, importante psiquiatra suíço devido a suas contribuições para o entendimento da esquizofrenia, o indivíduo se restringia a um mundo próprio e tinha uma perda de contato com a realidade, e isto ele chamou de autismo.

Correlacionando as falas de Freud e Bleuler, percebe-se que nenhum dos dois afirma que o autista tem uma perda total da realidade, só há a prevalência maior do mundo restrito deles do que ao mundo da relação com os demais seres humanos. Mas o autismo desvinculado da esquizofrenia surge somente em 1943, nomeado como 'autismo infantil precoce' com Kanner, 13 anos depois do famoso caso Dick de Melanie Klein. 


\section{CONGQEESSOCIENCIASSOCIEDADE \\ Inovação, Diversidaale e Sustentalililitadie}

ANAIS CBCS 2019 | 3 a 5 de outubro de 2019 | Centro Universitário Santo Agostinho - Teresina - P|

\section{METODOLOGIA}

O presente artigo consiste em uma revisão bibliográfica de caráter qualitativo a respeito do autismo tendo como objetivo geral expor toda a sua historicidade e discutir as dificuldades de intervenção na clínica psicanalítica contemporânea. Para isso foram acessados artigos disponíveis nas plataformas Scielo, Pepsic e Google Acadêmico. A pesquisa foi realizada através da busca pela temática: "Autismo"; "Psicologia clínica"; "Psicanálise". Foram selecionados 3 livros e 5 artigos onde todos abordavam a temática do autismo na clínica psicanalítica.

\section{RESULTADOS E DISCUSSÃO}

Antes de adentrar na discussão atual sobre o autismo, juntamente com a psicanálise, é necessário de antemão uma viagem pela historicidade de tal temática, para subsidiar a mesma em alguns saberes, valores e práticas clínicas do século passado. Inicia-se no ano de 1943 com sua descoberta pelo médico e psiquiatra Leo Kanner, que observou 11 crianças que foram diagnosticadas com intensa debilidade mental ou deficiência auditiva. (MAS, 2018)

Estes testes trouxeram dados de níveis baixos de inteligência, da falta de reações a estímulos sonoros ou uma resposta mais limitada, que fomentava e reafirmava o diagnóstico de surdez, mas um estudo mais aprofundado nessas características demonstrou que não havia deficiência auditiva. Kenner fez outras observações de comportamentos das crianças, sobre a particularidade da fala, o desejo, a fúria a partir de pequenas mudanças em suas rotinas dentre outras, mudando assim a classificação fenomenológica, saindo de esquizofrenia para outra categoria dos transtornos de neurodesenvolvimento, chamada de autismo. (MAS, 2018)

E que tem por definição atual no DSM-V, 2015:

caracteriza-se por déficits persistentes na comunicação social e na interação social em múltiplos contextos, incluindo déficits na reciprocidade social, em comportamentos não verbais de 


\section{conghesSO CIENCIAESOCIEDADE \\ -}

ANAIS CBCS 2019 | 3 a 5 de outubro de 2019 | Centro Universitário Santo Agostinho - Teresina - PI

comunicação usados para interação social e em habilidades para desenvolver, manter e compreender relacionamentos. Além dos déficits na comunicação social, o diagnóstico do transtorno do espectro autista requer a presença de padrões restritos e repetitivos de comportamento, interesses ou atividades. (MAS, 2018, p. 17 apud APA, 2015.p.31)

Depois dessa mudança taxonômica as discussões sobre a temática, seu diagnóstico, suas possíveis causas, tratamentos adequados para cada tipo de demanda só se intensificaram. Um dado interessante é o aumento súbito dos diagnósticos de autismo e suas subcategorias em uma marcação de 34 anos. Onde no DSM-III de 1980 foi primeiro a incluir o autismo como classificação, e naquela época existia afirmações havendo entre 2 a 4 casos de autismo em um total de 10 mil crianças. Diferente do ano 2014 que veio com um dado bruto de 1 caso de autismo a cada 68 crianças, um aumento exponencial e alarmante de acordo com CDC (Centers for Disease Control \& Prevention). (MAS, 2018)

Segundo Nelzira e Iracema (2015) trazem uma pauta bem interessante sobre as origens do autismo, suas causalidades, como a de multicausas (apud Schwartzman, 2011a), mas que ainda não há uma resposta pronta. Olhando pelo viés da psicoafetividade que as autoras apontam, que se dá por conta da constituição subjetiva do sujeito (apud Campanário \& Pinto, 2011; Rabello, 2004) como também as relações pelo contexto envoltório da criança (apud Hall, Nicholson, \& Adilof, 2006; Volk, Lurmann, Penfold, Hertz-Picciotto, \& McConnell, 2013). Por mais um ângulo, tem-se um viés de causas neurobiológicas, geneticamente determinadas, que o próprio nome sugere, causadas por condições genéticas (apud Mecca et al., 2011), modificações também cerebrais, podendo ocasionar as anomalias seria também uma causalidade (apud Bolton, Griffiths, \& Pickles, 2002), como também alterações em níveis neuronais (apud Kooten et al., 2008; Wang et al., 2009) ou até mesmo em escalas cromossômicas de modificações (apud Tarelho \& Assumpção, 2007).

\section{AUTISMO NA PSICANÁLISE}


ANAIS CBCS 2019 | 3 a 5 de outubro de 2019 | Centro Universitário Santo Agostinho - Teresina - P |

O caso Dick de Melanie Klein foi o primeiro caso de autismo na psicanalise no ano de 1930. Dick tinha 4 anos de idade e havia sido diagnosticado com Demência precoce. O mesmo não tinha desenvolvido eficazmente a formação de símbolos, importantíssima na teoria kleiniana pois este desenvolvimento permite que as emoções e fantasias das crianças se desloquem dos pais, chamados de objetos primários, para novos objetos com isso reduzindo a ansiedade e adquirindo desenvolvimento social. Este processo chamado sublimação possibilita a criança distanciar-se dos objetos primários, abrindo-se assim para o mundo.

Quando caracteriza-se um psicanalista sempre vem à mente os seguintes adjetivos: profissional calado, "arqueólogo", que espera vim à tona um material do inconsciente para a interpretação do sujeito, porém Klein teve que adaptar-se à demanda de Dick, já que o mesmo não tinha material simbólico organizado. A psicanalista criou um jogo de acordo com os interesses do garoto. Dick progressivamente evoluiu à cada sessão, demonstrando sinais de angústia e dependência, adquirindo um vocabulário mais variado e após seis meses Dick já conseguia demonstrar vinculação afetiva com seus pais e pessoas próximas, mas demonstrando sinais de angustia com a presença de estranhos.

A clínica psicanalítica sofreu ataques, enfatizava-se que a psicanálise compreendia o autismo de forma reducionista, afirmando que a causa do mesmo era única e exclusivamente à relação disfuncional mãe e bebê. Contudo nos últimos tempos psicanalistas buscaram ativamente conhecimentos em áreas contribuintes, atribuindo então a etiologia do autismo como multifatorial.

Sendo esses fatores multicausais, é possível encontrar a existência de várias obras que expõem uma variedade de definições que abrangem aspectos genéticos, psicogênicos, ambientais, e etc.; Entretanto, há também existência de publicações que afirmam que para a psicanálise a causa do autismo está além dos aspectos citados a cima, mas na causalidade significante produzida pela linguagem.

Gonçalves et al. (2017) realizaram uma pesquisa na qual puderam concluir que, a partir do diagnóstico na perspectiva psicanalítica é possível identificar práticas 


\section{CONGQEESSOCIENCIASSOCIEDADE

ANAIS CBCS 2019 | 3 a 5 de outubro de 2019 | Centro Universitário Santo Agostinho - Teresina - PI

orientadas para a observação dos comportamentos e a consideração da singularidade e subjetividade de cada sujeito, sua história de vida, seus desejos e a expressividade da sua convivência com o mundo externo, e que a psicanálise se mostra disposta a refletir sobre a importância de não se priorizar os aspectos cognitivos sobre os aspectos que organizam a personalidade.

\section{CONSIDERAÇÕES FINAIS}

A psicanálise foi uma grande contribuinte de conhecimento sobre o autismo, desde Freud e Bleuler, mesmo tendo sofrido inúmeras críticas. A clínica psicanalítica teve que adaptar-se ao sujeito autista, tendo em vista que sua forma tradicional era esperar manifestações do inconsciente e interpretá-las.

Algumas intervenções consideradas apropriadas para o tratamento dos autistas, são técnicas como o manejo da transferência, a reestruturação psíquica através do desenvolvimento da capacidade simbólica, e a ênfase no jogo simbólico. Práticas voltadas para a capacidade da linguagem também são possibilidades de intervenção. No tratamento, faz-se necessário destacar a importância da adaptação de técnica às características singulares do sujeito, a sua subjetividade, para que o tratamento possa alcançar melhores resultados, e que tanto o diagnóstico como o tratamento na visão Psicanalítica em sua maioria são voltados para infância.

É de extrema importância que o diagnóstico e acompanhamento do sujeito autista seja feito o quanto antes para evitar maiores danos ao desenvolvimento de linguagem, social e simbólico. Lembrando que as intervenções são feitas de modo subjetivo, adaptadas a cada sujeito respeitando as suas limitações. O quanto antes a criança for diagnosticada e receber acompanhamento adequado mais chances terá de conseguir desenvolver, até onde conseguir, as suas interações externas. 


\section{CONGERESSOCIENCIASSOCIEDADE \\ Inovaçã̃o, Diversidadie e Sustentahilitilaile}

ANAIS CBCS 2019 | 3 a 5 de outubro de 2019 | Centro Universitário Santo Agostinho - Teresina - P |

\section{REFERÊNCIAS}

AMERICAN PSYCHIATRIC ASSOCIATION. DSM-V. Manual Diagnóstico e Estatístico de Transtornos Mentais. Porto Alegre: ARTMED,2014, 5‥ed.

AZEVEDO, F.C. Autismo e Psicanálise: O lugar possível do analista na direção do tratamento. 1.ed. Curitiba: Juruá, 2011.

BRITTES, L. BRITTES, C. Mentes Únicas. São Paulo: Gente,2019.

GONCALVES, Amanda Pilosio et al . Transtornos do espectro do autismo e psicanálise: revisitando a literatura. Tempo psicanálise. Rio de Janeiro, v. 49, n. 2, p. 152-181, dez. 2017. Disponível em: <http://pepsic.bvsalud.org/scielo.php?script=sci_arttext\&pid=S0101$48382017000200008>$ Acessado em: 6 set. 2019.

GUEDES, N. P. S; TADA, I. N. C. A Produção Científica Brasileira sobre Autismo na Psicologia e na Educação. Psicologia: Teoria e Pesquisa. Disponível em: <http://www.scielo.br/pdf/ptp/v31n3/1806-3446-ptp-31-03-00303.pdf>. Acessado em: 3 set. 2019. LEIRAS,E. P. L; BATISTELL, F. M. V. Reflexões psicanalíticas sobre um caso com transtorno do espectro autista (TEA). Estilos clin. vol.19 no.2 São Paulo ago. 2014. Disponível em: <http://pepsic.bvsalud.org/scielo.php?script=sci_arttext\&pid=S1415$71282014000200004>$ Acessado em 24 de Agosto de 2019.

LUCERO, Ariana; VORCARO, A. M. R. Lacan Leitor de Melanie Klein: 0 Caso Dick em Questão. Psicologia: Teoria e Pesquisa Vol. 33, pp. 1-8. Disponível em:

<http://www.scielo.br/pdf/ptp/v33/0102-3772-ptp-33-e3348.pdf> Acessado em 29 de agosto de 2019

MAS, Natalie Andrade. Transtorno do Espectro Autista - História da construção de um diagnóstico. Tese (Mestrado Psicologia Clínica) do Instituto de Psicologia da USP. São Paulo, $2018 . \quad$ Disponível em: <https://teses.usp.br/teses/disponiveis/47/47133/tde-26102018-191739/ptbr.php > Acessado em 3 set. 2019. 